\title{
Post-extra systolic potentiation: Influence of calcium and verapamil in rat and rabbit hearts
}

\author{
J. P. Kerker, T. J. C. Ruigrok, J. H. M. Nieuwenhuijs*, C. Borst and F. L. Meijler \\ Department of Cardiology, University Hospital, Utrecht, The Netherlands * and the Department of \\ Physiology State University Utrecht, Utrecht, The Netherlands
}

KEY WORDS: PESP, calcium, calcium antagonist, contractility.

The interactions of the inotropic effects of verapamil $\left(0 \cdot 05-2 \cdot 0 \mu \mathrm{mol} \mathrm{l}^{-1}\right)$, calcium $\left(0 \cdot 33-5 \cdot 2 \mathrm{mmoll}^{-1}\right)$ and post extra systolic potentiation (PESP) as induced by paired stimulation were studied in isolated rabbit and rat hearts under isovolumic and isotonic conditions. At low doses of verapamil, contractions were depressed, but those elicited by paired stimulation showed less depression than contractions of the same rate during single stimulation and even exceeded the unpotentiated contractions without verapamil. At high doses of verapamil contractility could not be restored by paired stimulation. Although contractions were restored to control level by an increase in extra-cellular calcium they were still abnormal in the sense that PESP could not be elicited. The excitation-contraction $(e-c)$ uncoupling due to low calcium perfusion could be counteracted by paired stimulation but e-c uncoupling due to high dose verapamil could not be reversed by paired stimulation. Our results support the view that PESP does not only depend on augmented slow channel calcium influx but also on an enhanced calcium shift within the sarcoplasmic reticulum. We are doubtful about the idea that PESP can be used clinically to counteract the negative inotropic effect of high doses of verapamil.

\section{Introduction}

The mechanism by which an extrasystolic beat elicits potentiation of the next beat (post extra systolic potentiation, PESP) is not fully understood $^{[1-6]}$. During paired stimulation every regular cardiac contraction is followed by an extra systole. Therefore paired stimulation is a form of sustained PESP. The premature depolarization has to be induced early enough to be mechanically ineffective and thus there will be two depolarizations for one mechanical contraction ${ }^{[1,7]}$. Recently the clinical relevance of PESP has been re-emphasized ${ }^{[8]}$.

Excitation-contraction coupling and thus the relationship between cycle length and strength of contraction may be interpreted in terms of calcium ion movements ${ }^{[9-11]}$. The effect of calcium antagonists has been attributed to inhibition of these calcium ion movements ${ }^{[12]}$. In the present study the interactions of the inotropic effects of

Address for reprints: F. L. Meijler, Department of Cardiology, University Hospital, Catharijnesingel 101, 3511 GV Utrecht, The Netherlands.

Received for publication on 20 November 1984 and in revised form, 4 March 1985. verapamil, calcium and paired stimulation were investigated to explore further the mechanisms responsible for PESP and for the negative inotropic effect of verapamil.

\section{Materials and methods}

Perfusion experiments were carried out with isolated hearts of New Zealand white rabbits $(2500-3000 \mathrm{~g})$ and Wistar rats $(200-250 \mathrm{~g})$. The rabbits were anesthetized with sodium pentobarbital and heparinized. After isolation of the heart, the aorta and mitral orifice were cannulated ${ }^{[13]}$. An electric valve in the aortic cannula allowed for coronary perfusion $\left(37^{\circ} \mathrm{C} ; 60 \mathrm{mmHg}\right)$ during a controlled period of diastole, but was otherwise closed. An electric valve in the mitral cannula was opened during every diastolic pause. End-diastolic pressure was maintained at $4 \mathrm{mmHg}$. Intraventricular pressure during isovolumic contractions was measured with a Millar Mikro-Tip pressure transducer inserted via the mitral cannula. The rats were anesthetized with diethyl ether and heparinized. The hearts were quickly removed and subsequently perfused at $37^{\circ} \mathrm{C}$ by the Langendorff 
technique at a constant pressure of $75 \mathrm{mmHg}$. The isotonic contractions of the hearts were recorded as described earlier ${ }^{[14]}$.

The perfusion fluid reservoirs were connected to the aortic cannula by means of a specially designed stopcock allowing successive use of the reservoirs. The standard perfusate had the following composition (mmol ${ }^{-1}$ ): $\mathrm{NaCl}, 124: \mathrm{KCl}, 4 \cdot 7 ; \mathrm{CaCl}_{2}$, $1.3 ; \mathrm{MgCl}_{2}, 1 \cdot 0 ; \mathrm{NaHCO}_{3}, 24 \cdot 0 ; \mathrm{Na}_{2} \mathrm{HPO}_{4}, 0.5$; glucose, 11.0 . The perfusion fluids were equilibrated with $95 \% \mathrm{O}_{2}-5 \% \mathrm{CO}_{2}$ to provide a $\mathrm{pO}_{2}$ of $>600 \mathrm{mmHg}$, and had a $\mathrm{pH}$ of $7 \cdot 40 \pm 0 \cdot 05$. When required, $0 \cdot 05-2 \cdot 0 \mu \mathrm{moll}^{-1}$ verapamil was added to the perfusate. In a number of experiments the $\mathrm{CaCl}_{2}$ concentration was increased to 2.6 or $5.2 \mathrm{mmol} \mathrm{l}^{-1}$, or decreased to 0.65 or $0.33 \mathrm{mmoll}^{-1}$.

The left ventricular electrogram was recorded by means of bipolar epicardial electrodes connected to a Gould amplifier and a Gould Brush 2800 ink recorder. To prevent interference with propagated sinus beats the atria were partially removed and atrioventricular conduction was blocked by means of an iron clip in the interventricular septum of the rat heart and by cauterizing the His bundle in the rabbit heart. Right ventricular stimulation well above threshold with impulses of $1 \mathrm{~mA}$ with a duration of $1 \mathrm{~ms}$ were applied. In the rabbit hearts the following protocol was applied: single stimulation for $10-15 \mathrm{~min}$ at a frequency of $1 \mathrm{~Hz}$, paired stimulation for $10 \mathrm{~s}$ using stimulus pairs of equal strength and duration with intervals of 200 and $800 \mathrm{~ms}$ alternatively, followed by single stimulation until steady state was reached. Subsequently the perfusion was changed to a medium containing
$0 \cdot 2$ or $1.0 \mu \mathrm{moll}^{-1}$ verapamil, and after $20 \mathrm{~min}$ of equilibration the same protocol was repeated. In the rat hearts the following protocol was applied: single stimulation for $10-15 \mathrm{~min}$ at a frequency of $2 \mathrm{~Hz}$, paired stimulation for $30 \mathrm{~s}$ with intervals of 70 and $430 \mathrm{~ms}$ alternatively, single stimulation at $2 \mathrm{~Hz}$ until steady state was reached, followed by single stimulation for $3 \mathrm{~min}$ at $4 \mathrm{~Hz}$. Subsequently the perfusion was changed to a medium containing $0 \cdot 05-2 \cdot 0 \mu \mathrm{moll}^{-1}$ verapamil, $0 \cdot 2 \mu \mathrm{moll}^{-1}$ verapamil and $2.6 \mathrm{mmol}^{-1}$ calcium, or $1.0 \mu \mathrm{mol}^{-1}$ verapamil and $5.2 \mathrm{mmoll}^{-1}$ calcium, and after $20 \mathrm{~min}$ of equilibration the same protocol was repeated.

\section{STATISTICAL ANALYSIS}

Data are presented as means \pm standard error of the mean (SEM). Statistical significance was determined by the Wilcoxon signed rank test. A $P<0.05$ was considered to indicate a significant difference between means.

\section{Results}

INFLUENCE OF VERAPAMIL IN THE RABBIT HEART

The peak isovolumic intraventricular pressure during single stimulation in the rabbit hearts amounted to $67 \pm 8 \mathrm{mmHg}$ (mean \pm SEM; $n=8$ ). During paired stimulation it increased to $110 \pm$ $12 \mathrm{mmHg}$. Figures 1 and 2 show the effect of $0 \cdot 2$ and $1.0 \mu \mathrm{mol}^{-1}$ verapamil on the unpotentiated and potentiated contractions. During perfusion with $0 \cdot 2 \mu \mathrm{mol}^{-1}$ verapamil, paired stimulation still increased the pressure above the level of single stimulation before addition of verapamil,
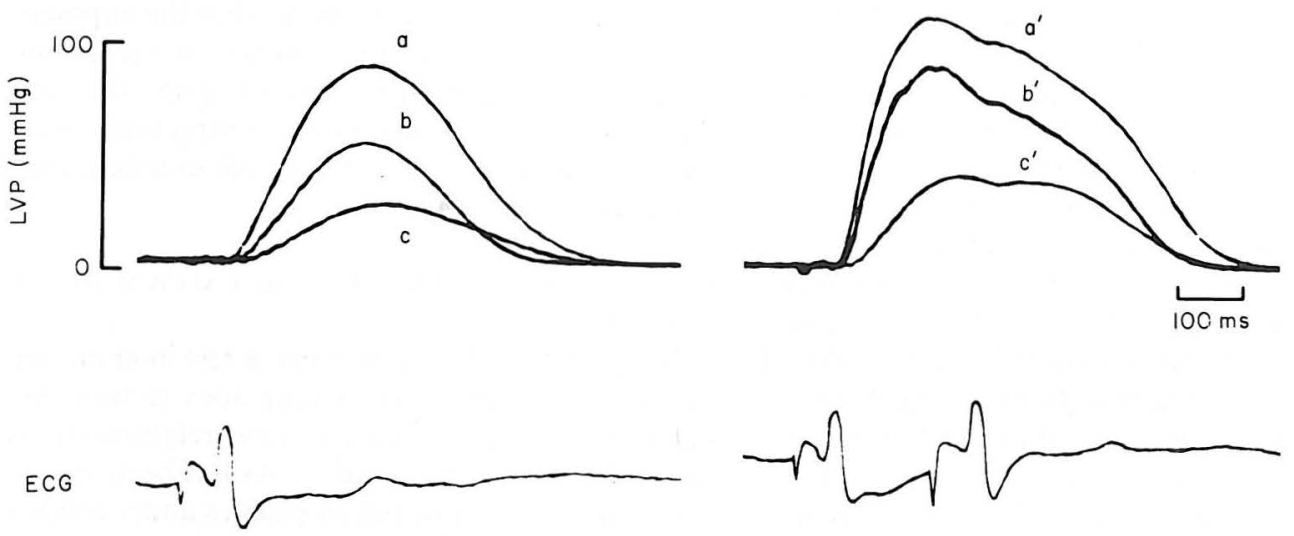

Figure 1 The intraventricular pressure of the rabbit heart during single stimulation (left panel) and paired stimulation (right panel), without verapamil (a and $\mathrm{a}^{\prime}$ ), with $0 \cdot 2 \mu \mathrm{mol} 1^{-1}$ verapamil (b and $b^{\prime}$ ), and with $1.0 \mu \mathrm{moll}^{-1}$ verapamil (c and $\mathrm{c}^{\prime}$ ). Original tracings of a representative experiment are photographically superimposed. 


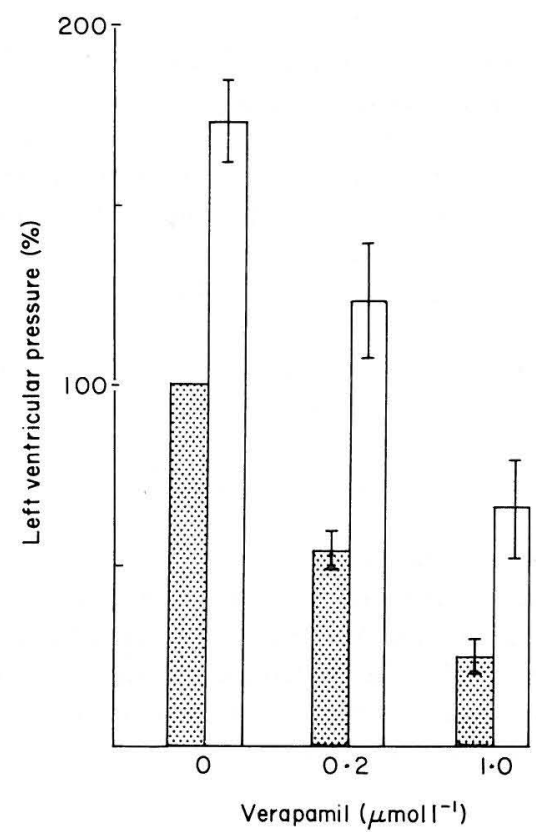

Figure 2 The relative effect of verapamil $(0.2$ and $\left.1 \cdot 0 \mu \mathrm{mol}^{-1}\right)$ on the peak systolic intraventricular pressure of the rabbit heart during single and paired stimulation. Intraventricular pressure was compared to the initial unpotentiated contractions before verapamil was added ( $100 \%$ level). The data indicate mean \pm SEM of 8 hearts. The coarsely dotted column indicates single stimulation. The empty column indicates paired stimulation.

whereas paired stimulation during perfusion with $1.0 \mu \mathrm{mol}^{-1}$ verapamil, although still causing considerable potentiation, was unable to equal this level. In Fig. 3 the depression by verapamil during single stimulation was compared with that during paired stimulation. For both verapamil concentrations the depression of the potentiated contractions was significantly less than that of the unpotentiated contractions $(P<0 \cdot 05)$.

\section{INFLUENCE OF VERAPAMIL IN THE RAT HEART}

The effect of six concentrations of verapamil at a calcium concentration of $1.3 \mathrm{mmol}^{-1}$ in the perfusion fluid on the unpotentiated and potentiated contractions of rat hearts is shown in Fig. 4. Before exposure to verapamil, the height of the potentiated contractions amounted to $165 \pm 5 \%$ of the unpotentiated contractions. After $30 \mathrm{~s}$ of paired stimulation, resumption of single stimulation resulted in a transient post-stimulation depression. Recovery was always complete before verapamil was added. Increasing the stimulation frequency

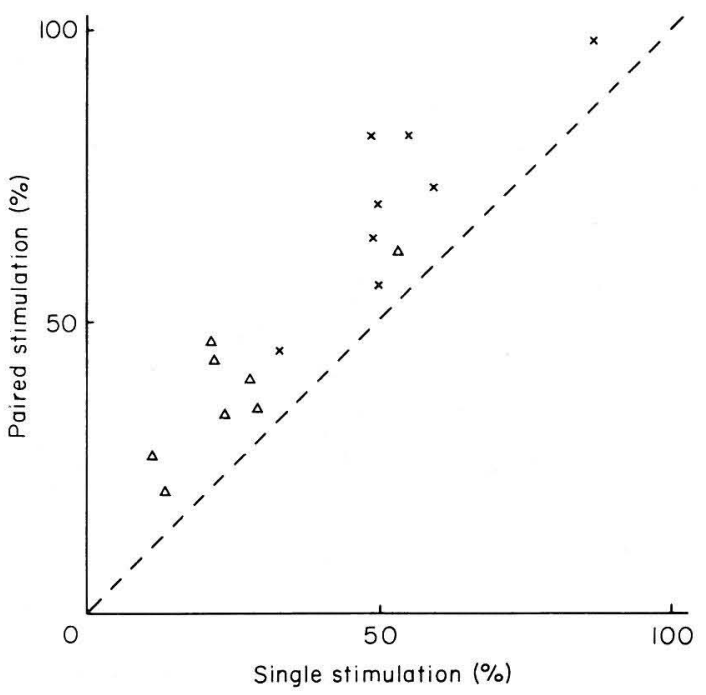

Figure 3 The relative effect of verapamil on the peak systolic intraventricular pressure of isovolumically contracting rabbit hearts $(N=8)$ during single stimulation at $1 \mathrm{~Hz}$ and paired stimulation. Intraventricular pressure before verapamil was $100 \%$. The broken line is the line of identity. Verapamil concentration in $\mu \mathrm{mol} \mathrm{l}^{-1}: x=0 \cdot 2, \Delta=1 \cdot 0$.

from 2 to $4 \mathrm{~Hz}$ resulted in a transient increase in contraction height. After 3 min a new steady state was reached, which did not differ significantly from the contraction height at $2 \mathrm{~Hz}$. The cardiodepressive effect of verapamil was concentration dependent and more pronounced at higher stimulation rates. At verapamil concentrations of $0.2 \mu \mathrm{mol}^{-1}$ and higher, paired stimulation caused considerable potentiation but failed to bring the contraction height back to the level of the unpotentiated contractions in the absence of verapamil. At verapamil concentrations of $0.05,0.1$ and $0.2 \mu \mathrm{moll}^{-1}$, the potentiated contractions were significantly less depressed than the unpotentiated contractions $(P<0.05)$ (Fig. 5).

\section{INTERACTION OF VERAPAMIL AND CALCIUM IN THE RAT HEART}

In Fig. 6 the relation between a test interval (see insert: $\mathrm{x}$ ) and the corresponding apex to base displacement is demonstrated. This relationship is called the restitution curve ${ }^{[15]}$. As has been shown previously ${ }^{[16]}$, the restitution kinetics under control conditions first follow a nearly exponential curve with a time constant of about $300 \mathrm{~ms}$, reaching a plateau at 1 to $2 \mathrm{~s}$, sometimes via a slight overshoot. Paired stimulation resulted in an upward 


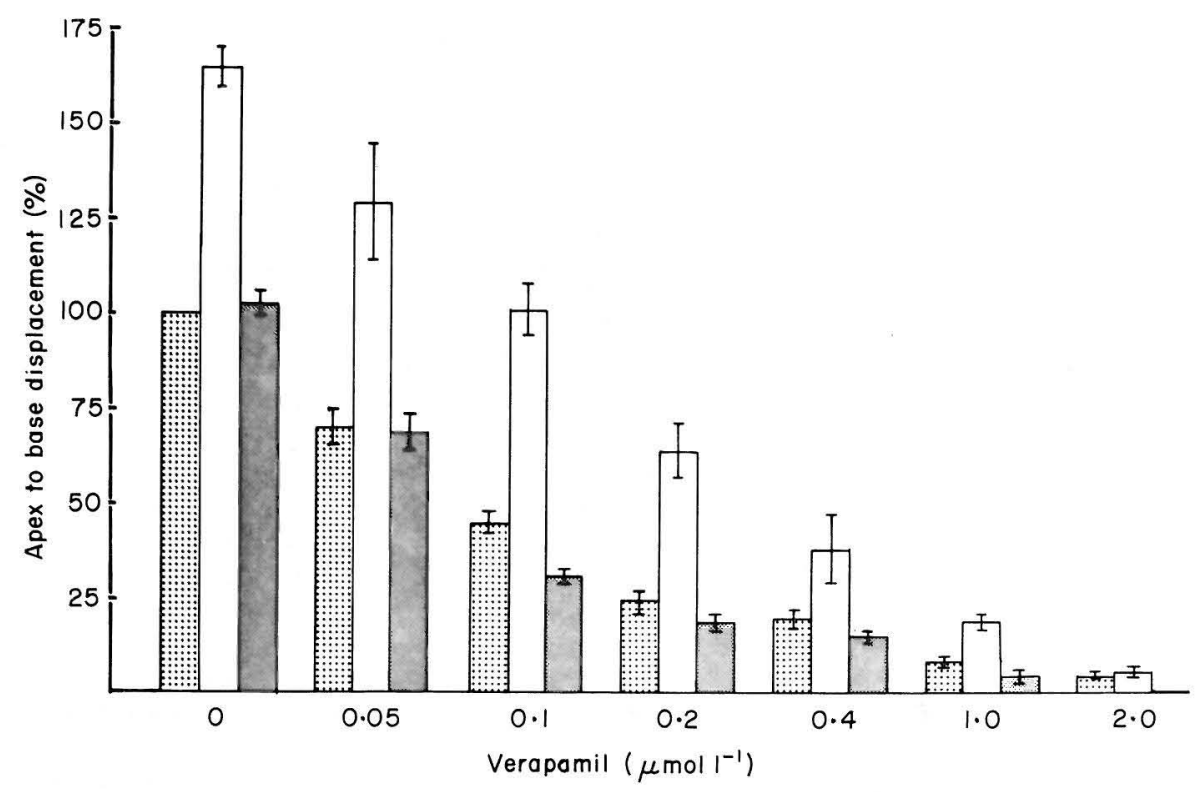

Figure 4 The relative effect of verapamil $\left(0 \cdot 05-2 \cdot 0 \mu \mathrm{mol}^{-1}\right)$ on the apex to base displacement of rat hearts at different stimulation patterns. Displacement was compared to the initial unpotentiated displacement $(100 \%$ level). The data indicate mean \pm SEM of 8 hearts in each group. The coarsely dotted column indicates single stimulation at $2 \mathrm{~Hz}$, the empty column indicates paired stimulation, the finely dotted column indicates single stimulation at $4 \mathrm{~Hz}$.

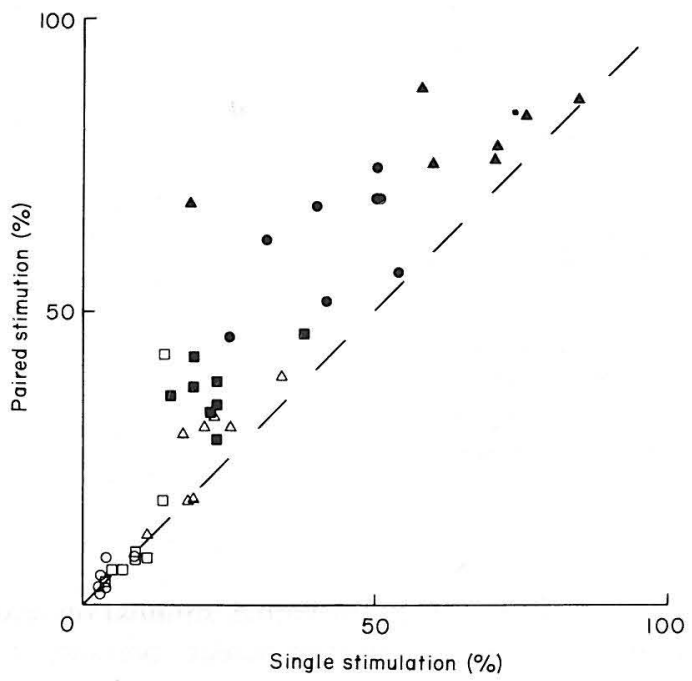

Figure 5 The relative effect of verapamil $\left(0 \cdot 05-2 \cdot 0 \mu \mathrm{moll}^{-1}\right)$ on the apex to base displacement of rat hearts $(n=8)$ during single stimulation at $2 \mathrm{~Hz}$ and paired stimulation. Displacement before verapamil was $100 \%$. The broken line is the line of identity. Verapamil concentration in $\mu \mathrm{mol} 1^{-1}: \Delta=0.05, \quad=0.1, \square=0.2, \Delta=0.4, \square=1 \cdot 0$, $\mathrm{O}=2 \cdot 0$. shift of the restitution curve ${ }^{[16]}$ [Fig. 6(a)], whereas verapamil and low calcium resulted in a downward shift of the restitution curve $\mathrm{e}^{[1,18]}[$ Fig. 6(c) and (d)]. When the verapamil induced depression of contractions during single stimulation was normalized by an increased calcium concentration, paired stimulation was unable to produce a further upward shift of the restitution curve [Fig. 6(b)]. Verapamil $\left(0 \cdot 2 \mu \mathrm{mol}^{-1}\right)$ and a low calcium concentration $\left(0.65 \mathrm{mmoll}^{-1}\right)$ caused an almost identical downward shift of the restitution curve [Fig. 6(c) and (d)]. Paired stimulation potentiated contractions more in low-calcium depressed than in verapamil depressed rat hearts [Fig. 6(c) and (d), Fig. 7]. When depressed contractions due to high concentrations of verapamil were normalized by an increased calcium concentration, a further effect of paired stimulation could not be obtained.

\section{Discussion}

In our experiments, paired stimulation of rat hearts could overcome the negative inotropic effect 


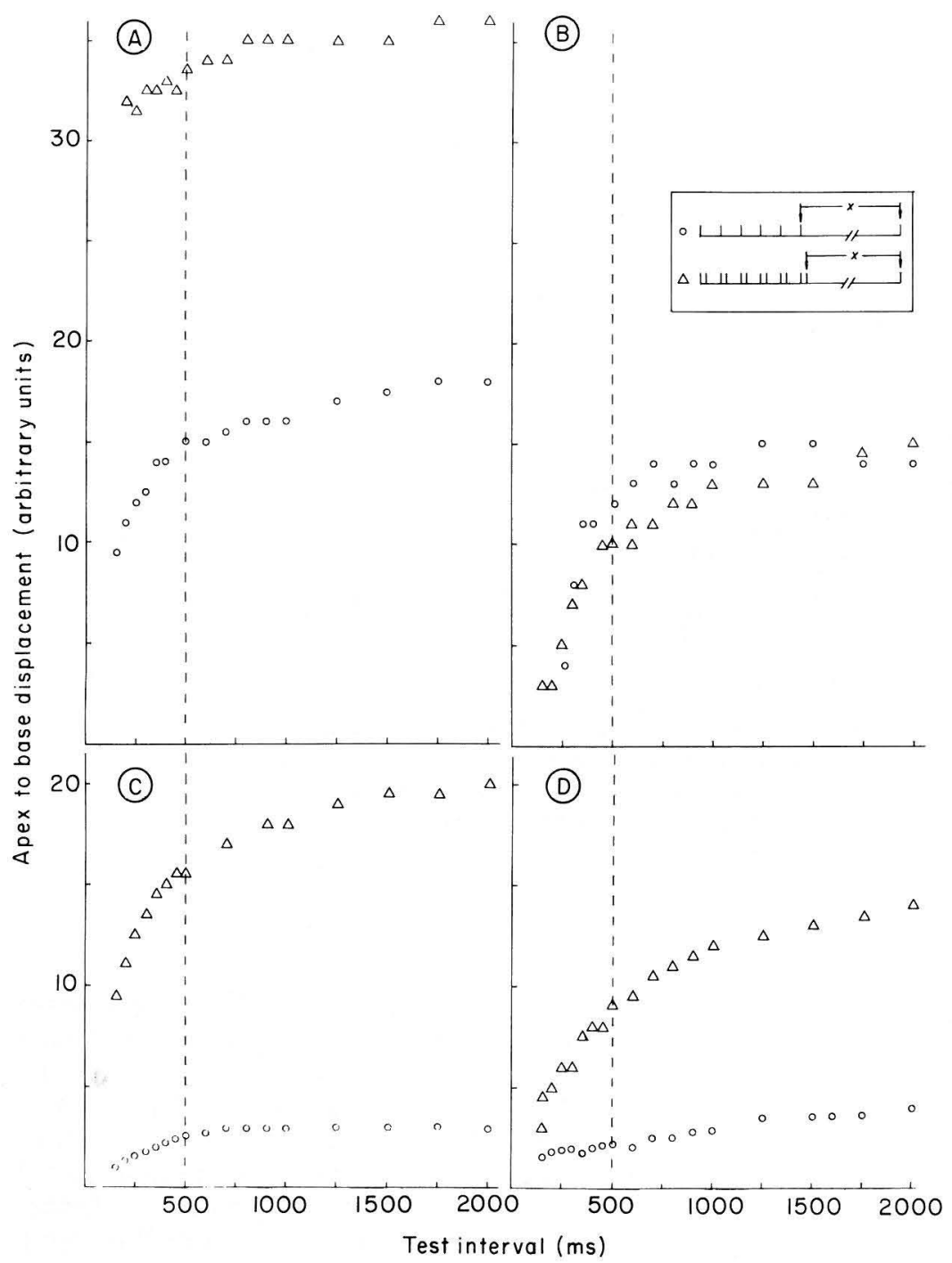

Figure 6 The influence of verapamil and calcium on apex to base displacement-test interval relationships of a single isotonic contraction following single (intervals $500 \mathrm{~ms}$ ) or paired (intervals 70 and $430 \mathrm{~ms}$ ) stimulation of an isolated rat heart. (a) control, (b) verapamil $1 \cdot 0 \mu \mathrm{mol}^{-1}$ and calcium $5.2 \mathrm{mmol}^{-1}$, (c) calcium $0.65 \mathrm{mmol}^{-1}$, (d) verapamil $0 \cdot 2 \mathrm{moll}^{-1}$.

of 0.05 and $0.1 \mu \mathrm{moll}^{-1}$ verapamil, bringing the contraction height above the level of the unpotentiated contraction in the absence of verapamil. At the higher verapamil concentrations, however, paired stimulation was unable to restore contraction height to control levels. In the rabbit hearts, paired stimulation at $0.2 \mu \mathrm{moll}^{-1}$ verapamil restored the intraventricular pressure till above the level of single stimulation without verapamil but at $1.0 \mu \mathrm{moll}^{-1}$ verapamil paired stimulation was unable to restore intraventricular pressure to control levels.

In a previous study ${ }^{[18]}$ it was demonstrated that paired stimulation can overcome in part the e-c uncoupling induced by low calcium perfusion $\left(0.3 \mathrm{mmol}^{-1}\right)$. The present study shows that paired stimulation cannot do so if e-c uncoupling has been caused by high doses of verapamil. Our 

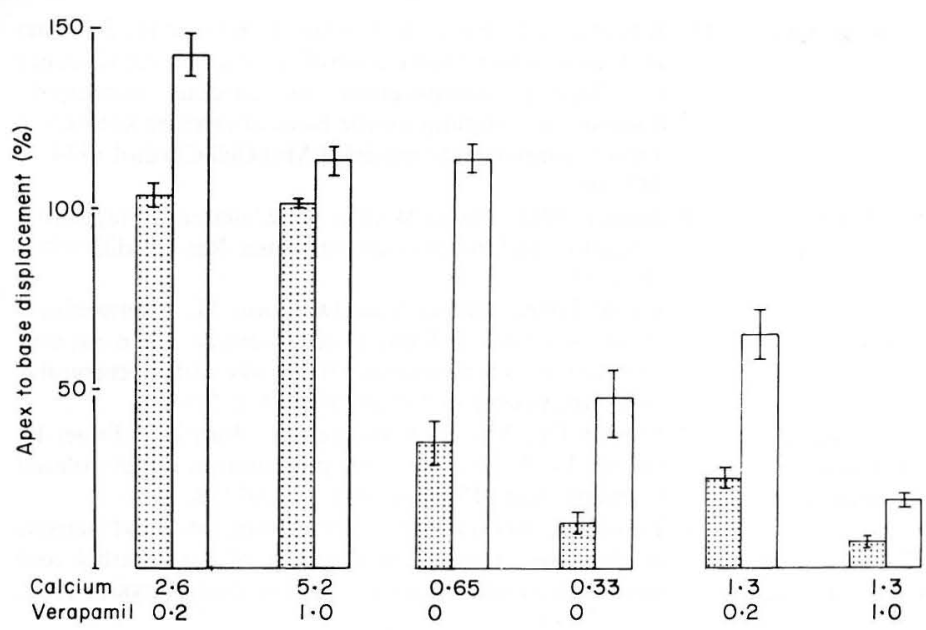

Figure 7 The effect of simultaneous addition of verapamil and increase of the calcium concentration (left), a decreased calcium concentration (middle), and verapamil (right) on the apex to base displacement during single and paired stimulation. Apex to base displacement was compared to the initial unpotentiated displacement during standard perfusion ( $100 \%$ level). The data indicate mean $\pm S E M$ of 8 rat hearts in each group.

data slightly differ from the results of Wiggins et $a l^{[4]}$, obtained from papillary muscles and trabeculae carneae of dog, cat and pig-tail monkey hearts. These authors demonstrated that paired stimulation in the presence of high doses of verapamil $\left(1 \mu \mathrm{mol1}^{-1}\right)$ brought the force of contraction to a level exceeding that of an unpotentiated contraction without verapamil. Given our results (Figs 1-5) with isolated perfused hearts we are doubtful about the idea that paired stimulation could be used clinically to counteract the negative inotropic effect of high doses of verapamil.

When contraction height was equally depressed by either low calcium or verapamil, the restoring effect of paired stimulation was less pronounced in the latter [Fig. 6(c) and (d), Fig. 7]. At the higher verapamil concentration paired stimulation could not restore contractility, while an increased calcium concentration could [Figs 6(b) and 7]. In these restored contractions, however, no further potentiation could be elicited by PESP, unveiling an abnormal contractile behaviour.

It has been suggested that potentiation induced by paired stimulation is mediated not only by an increased transfer of calcium across the cell membrane, but also by an enhanced shift of calcium inside the sarcoplasmic reticulum from uptake to release sites ${ }^{[5,6,19]}$. This could explain the upward shift of the restitution curve $\mathrm{e}^{[15,16,19]}$. Verapamil is not only a slow channel blocker but may also slow down the kinetics of calcium reavailability from these internal stores ${ }^{[17]}$. Our results show that low doses of verapamil $\left(0.05-0.2 \mu \mathrm{moll}^{-1}\right)$ had less effect on the contractions during paired stimulation than on those during single stimulation. Since the inhibition of the slow calcium channels is more pronounced at a higher stimulation rate ${ }^{[20]}$, a more prenounced effect of verapamil would be expected during paired stimulation, if an increased transfer of calcium across the cell membrane were the only mechanism of PESP. However if PESP is also mediated by an enhanced shift of calcium inside the sarcoplasmic reticulum, this effect may be counteracted in a dose-related way by verapamil. Possibly, this intracellular effect of verapamil cannot be overcome by an increased extracellular calcium concentration. This would imply that neither the term 'slow channel blocker' nor 'calcium antagonist' is fully appropriate to describe the mechanisms of action of verapamil ${ }^{[12]}$. It might also explain the reported failure of calcium infusion in the treatment of severe verapamil poisoning $^{[21]}$.

In conclusion, our results are compatible with the view that PESP depends not only on an augmented calcium influx through the slow channels, but also on an enhanced calcium shift within the sarcoplasmic reticulum. Verapamil in high doses 
abolishes the positive inotropic effect of paired stimulation.

\section{References}

[1] Cranefield PF. The force of contraction of extrasystoles and the potentiation of force of the postextrasystolic contraction: a historical review. Bull NY Acad Med 1965; 41: 419-27.

[2] Cranefield PF. The present status of paired pulse stimulation and postextrasystolic potentiation in the heart. Bull NY Acad Med 1965; 41: 736-47.

[3] Suko J, Ueba Y, Chidsey CA. I. Intracellular calcium and myocardial contractility. II. Effects of postextrasystolic potentiation in the isolated rabbit heart. Circ Res 1970; 27: 227-34.

[4] Wiggins JR, Leary JM, Cranefield PF. The effects of verapamil and paired pulse stimulation on mammalian ventricle. Eur J Cardiol 1975; 3: 181-5.

[5] De Mello WC. Post-extrasystolic potentiation; effect of $\mathrm{Ca}$, histamine, caffeine and epinephrine. Arch Int Pharmacodyn Ther 1977; 230: 235-44.

[6] Iinuma $\mathrm{H}$, Kato $\mathrm{K}$. The effects of extracellular potassium and several drugs on the premature action potential and postextrasystolic potentiation. Eur J Cardiol 1978; 7: 465-77.

[7] Hoffman BF, Bartelstone HJ, Scherlag BJ, Cranefield PF. Effects of postextrasystolic potentiation on normal and failing hearts. Bull NY Acad Med 1965; 41: 498-534.

[8] Meijler FL, Kuijer PJP, Van Dam-Koopman I, Heethaar RM, Van der Werf T. Clinical relevance of postextrasystolic potentiation. Mayo Clin Proc 1982; 57 (Suppl): 34-40.

[9] Wood EH, Heppner RL, Weidmann S. Inotropic effects of electric currents I. Positive and negative effects of constant electric currents or current pulses applied during cardiac action potentials II. Hypotheses: calcium movements, excitation-contraction coupling and inotropic effects. Circ Res 1969; 24: 409-45.

[10] Morad M, Goldman Y. Excitation-contraction coupling in heart muscle: membrane control of development of tension. Prog Biophys Mol Biol 1973; 27: 259-313.
[11] Kaufmann R, Bayer R, Fürniss T, Krause H, Tritthart $\mathrm{H}$. Calcium movement controlling cardiac contractility II. Analog computation of cardiac excitationcontraction coupling on the basis of calcium kinetics in a multicompartment model. J Mol Cell Cardiol 1974; 6: $543-59$.

[12] Nayler WG, Poole-Wilson P. Calcium antagonists: definition and mode of action. Basic Res Cardiol 1981; 76: $1-15$.

[13] Boom HBK, Denier Van Der Gon JJ, Nieuwenhuijs JHM, Schiereck P. Cardiac contractility: Actin-myosin interaction as measured from the left ventricular pressure curve. Eur J Cardiol 1973; I: 217-24.

[14] Meijler FL, Van Den Bogaard F, Van Der Tweel H, Durrer D. Postextrasystolic potentiation in the isolated rat heart. Am J Physiol 1962: 202: 631-5.

[15] Kruta V, Braveny P. Performance of heart muscle in rhythmic activity. Restitution of contractility and potentiation phenomena. Proc Int Cong Physiol 1962; 22: $137-43$.

[16] Meijler FL, Nieuwendijk ES, Durrer D. Physiological basis of paired stimulation potentiation. In: Cranefield PF, Hoffman BF, eds. Paired pulse stimulation of the heart. New York: The Rockefeller University Press, 1968: 65-71.

[17] Bayer R, Hennekes R, Kaufmann R, Mannhold R. Inotropic and electrophysiological actions of verapamil and D600 in mammalian myocardium I. Pattern of inotropic effects of the racemic compounds. Naunyn Schmiedebergs Arch Pharmacol 1975; 290: 49-68.

[18] Nieuwendijk ES, Meijler FL, Durrer D. Influence of paired stimulation on the electromechanical dissociation during low calcium perfusion of isolated rat hearts. Cardiovasc Res 1967; 1: 308-12.

[19] Pidgeon J, Lab M, Seed A, Elzinga G, Papadoyannis D, Noble MIM. The contractile state of cat and dog heart in relation to the interval between beats. Circ Res 1980; 47: 559-67.

[20] Ehara T, Kaufmann R. The voltage- and timedependent effects of $(-)$ verapamil on the slow inward current in isolated cat ventricular myocardium. J Pharmacol Exp Ther 1978; 207: 49-55.

[21] Crump BJ, Holt DW, Vale JA. Lack of response to intravenous calcium in severe verapamil poisoning. Lancet 1982; ii: 939-40. 